\title{
Los dibujos de los niños fueron útiles en el diagnóstico de cefalea
}

The Uselfulness of Children's Drawings in the Diagnosis of Headhache. Stafstrom C, Rostasy K, Minster A. Pediatrics 2002;109:460472

\section{Objetivo}

Determinar si los dibujos pueden ayudar en el diagnóstico diferencial de cefaleas en los niños.

\section{Diseño}

Estudio de corte transversal

\section{Lugar}

Departamento de Neurología Infantil de la Universidad Tufts, Boston, EEUU.

\section{Pacientes}

226 niños consecutivos de 4 a 19 años (media +/- DS:11.4 +/- 3,4 años) que consultaron por cefalea.

\section{Descripción del test y del test de referencia (gold standard)} Antes de iniciar el interrogatorio, se les solicitó a los niños que realizaran un dibujo que mostr ara como se sentían cuando tenían dolor de cabeza. Se les dijo "Por favor, dibujate a vos mismo teniendo un dolor de cabeza. ¿Dónde te duele? ¿Cómo te hace sentir el dolor? ¿Hay algún otro cambio o síntoma que venga antes o durante el dolor de cabeza que vos quieras mostrarme en el dibujo?". Si el niño sufría de más de un tipo de dolor de cabeza se le preguntaba si quería hacer otro dibujo describiendo cada tipo.Se les dio una hoja blanca tamaño carta, un lápiz negro №2 y una goma.Los dibujos fueron clasificados como "migraña" y "no migraña" por pediatras especialistas en Neurología, quienes eran ciegos a la historia clínica de los pacientes. El diagnóstico clínico del tipo de cefalea (gold standard) fue realizado independientemente por otro neurólogo infantil, utilizando el interrogatorio usual y el examen físico. No hubo referencia a criterios específicos de migraña.

\section{Resultados}

Comparado con el diagnóstico clínico, los dibujos tuvieron una sensibilidad del $93,1 \%$, una especificidad del $82,7 \%$, un valor predictivo positivo (VPP) del $87,1 \%$ y un valor predictivo negativo (VPN) del 90,6\% para migraña. Los hallazgos específicos asociados a migraña como signos neurológicos focales, síntomas visuales (f otofobia, escotomas), dolor periorbital o náuseas/vómitos tuvieron un VPP de $>90 \%$ para migraña; el dolor severo o en puntada tuvo un VPP de $>80 \%$ para migraña. El dolor en vincha no fue predictivo para migraña (VPP de $11,1 \%$ ). Las realizaciones que contenían dibujos de tristeza o llanto no diferenciaban migraña de cefalea no migrañosa.

Comparación de diagnóstico clínico y por dibujos de cefalea ( $n=235$ dibujos)

\begin{tabular}{l|c|c}
\hline \multirow{2}{*}{ Diagnóstico por dibujos } & \multicolumn{2}{|c}{ Diagnóstico clínico } \\
\cline { 2 - 3 } & Mligraiña & No migraña \\
\hline Test positivo (dibujos & Verdaderos positivos & Falsos positivos \\
de migraña) Total : 139 & 69 mujeres +52 varones $=121$ & 7 mujeres +11 varones $=18$ \\
\hline Test negativo (dibujos de & Falsos negativos & Verdaderos negativos \\
no migraña) Total: 96 & 6 mujeres +3 varones $=9$ & 45 mujeres + 42 varones $=87$ \\
\hline
\end{tabular}

\section{Conclusiones}

Los dibujos realizados por los niños son un recurso simple y barato que ayuda en el diagnóstico del tipo de cefalea, con una sensibilidad, especificidad y valor predictivo muy alto para diferenciar la migraña de la cefalea no migrañosa.

\section{Comentario}

La cefalea es un motivo de consulta frecuente en pediatría.Entre las causas más frecuentes podemos mencionar a la cefalea tensional y a la migraña, variando la tasa de prevalencia en los niños desde un 1 al $10 \% 1$. En estos pacientes generalmente se ve afectada la performance académica, memoria, personalidad y relaciones interpersonales, como también en la atención escolar 12

Realizar un diagnóstico diferencial adecuado es útil ya que el enfoque terapéutico va a depender de la causa de la cefalea. El diagnóstico de migraña es clínico. La Sociedad Internacional de Cefalea ha publicado los criterios diagnóstico para varios tipos de cefalea en adultos. ${ }^{4}$ Se ha propuesto modificar estos criterios para los chicos para mejorar la sensibilidad manteniendo la especificidad. $56 \mathrm{Com}$ parados con los adultos los niños tienen mayor dificultad para expresar los síntomas, la migraña dura menos tiempo, menos frecuentemente es unilateral y con presencia de aura y con más frecuencia presenta síntomas asociados (náuseas, vómitos, dolor abdominal, mareos, etc.). En la práctica, al igual que en este artículo, el diagnóstico se hace en base al interrogatorio, examen físico y juicio clínico.

La duda para la aplicación de esta maniobra en el consultorio de atención primaria es si hay que ser neurólogo infantil para interpretar tan eficazmente el dibujo. Aún así, esta maniobra es muy barata, no requiere de demasiado tiempo y de surgir dudas, puede acompañar al paciente en caso de necesitar realizar una interconsulta (la mayoría de los niños con cefalea intensa y/o aquellos que requieran realizar tratamiento profiláctico serán consultados a un neurólogo infantil).

Conclusión del comentario: Si bien el diagnóstico de migraña debe realizarse siguiendo criterios establecidos, utilizar este método de expresión de los niños a través de los dibujos podría ser una herramienta útil como ayuda en el diagnóstico diferencial, reaseguro del paciente y de sus padres.

\section{Dr. Federico Anibal Bugatti [ Unidad de Medicina Familiar y Salud Comunitaria.Htal. Menor de Ing.White de Bahía Blanca ]}

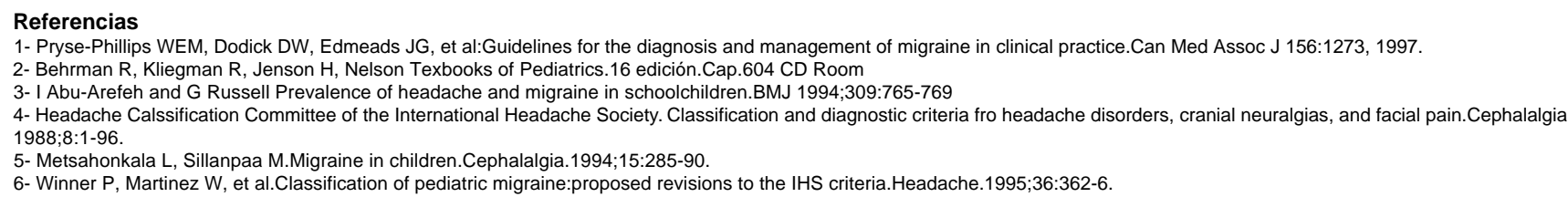

